"Fl suler ide mis hiipses

Año 13.

Núm. 33

https://revistainvestigacionacademicasinfrontera.unison.mx/index.php/RDIASF

Recibido el 4 de junio de 2020. Dictaminado mediante arbitraje favorablemente 16 de diciembre de 2020.

\title{
ANÁLISIS DE LOS FACTORES DE ATRACTIVIDAD TERRITORIAL PERCIBIDA: CASO DE ESTUDIO HUATABAMPO, SONORA.
}

\author{
Dr. José César Kaplan Navarro \\ Jose.kaplan@ues.mx \\ Universidad Estatal de Sonora, Unidad Académica Navojoa \\ ORCID 0000-0002-1365-0569 \\ Dr. Gustavo César Hermosillo Anduaga \\ Universidad Estatal de Sonora, Unidad Académica Navojoa \\ gustavocesar@gmail.com \\ ORCID 0000-0002-4482-4058 \\ Dr. Hugo Neftalí Padilla Torres \\ Universidad Estatal de Sonora, Unidad Académica Navojoa \\ hugo.padilla@ues.mx \\ ORCID 0000-0003-1091-0115 \\ LC. José Heriberto Campoy Palomares \\ Universidad Estatal de Sonora, Unidad Académica Navojoa \\ Heri.campoy@gmail.com \\ ORCID 0000-0001-6041-940X
}

\begin{abstract}
Resumen
Este artículo tiene como objetivo analizar la percepción que los empresarios tienen de los factores de atractividad territorial que influyen en la selección del municipio de Huatabampo para la inversión productiva. La dinámica que ha generado el sector empresarial por tomar decisiones del lugar geográfico a invertir, no solo se restringe a los recursos naturales que este territorio ofrece, sino que hay otros aspectos de carácter cualitativo que son igualmente importantes. En ese sentido,
\end{abstract}


"Fl sulber ide mis hijise

Año 13.

Núm. 33

https://revistainvestigacionacademicasinfrontera.unison.mx/index.php/RDIASF
Revista de Investigación

Académica sin Frontera

ISSN: 2007-8870

Recibido el 4 de junio de 2020. Dictaminado mediante arbitraje favorablemente 16 de diciembre de 2020.

los gobiernos locales han iniciado una competencia por hacer ver su territorio más atractivo que los demás. En la ciudad de Huatabampo se analizaron nueve factores de atractividad: Recursos humanos, infraestructura, empresas, investigación y desarrollo, mercado, política fiscal, instituciones, gobierno y marco jurídico y social. Se encontró que de estos nueve factores solamente el factor de recursos humanos fue considerado como aceptable obteniendo una calificación de 3.77; el resto de los factores no superó el nivel mínimo de 3.5 por lo que se consideran inaceptables. Los factores con las más bajas calificaciones fueron: Gobierno e Instituciones con una calificación de 2.49 y 2.50 respectivamente. En conclusión la ciudad de Huatabampo presenta varias áreas de mejora que deben ser atendidas si se desea tener un nivel de atractividad territorial aceptable que genere condiciones de atracción constante de flujos de inversión productiva.

Palabras Clave: Competitividad, atractividad.

\title{
TERRITORIAL ATTRACTIVENESS: ANALYSIS OF PERCEPTION FACTORS THAT INCIDE ON THE MUNICIPALITY OF HUATABAMPO, SONORA, MEXCICO
}

\begin{abstract}
This article aims to analyze the perception that investors have of the factors of territorial attractiveness that influence the selection of the municipality of Huatabampo for productive investment. The dynamics that the business sector has generated by making decisions about the geographical place to invest is not only restricted to the natural resources that this territory offers, but there are other qualitative aspects that are equally important. In this sense, local governments have started a competition to make their territory see more attractive than others.
\end{abstract}


"Fl silwer ile mis hijics

Año 13.

Núm. 33

https://revistainvestigacionacademicasinfrontera.unison.mx/index.php/RDIASF
Revista de Investigación

Académica sin Frontera

ISSN: 2007-8870

Recibido el 4 de junio de 2020. Dictaminado mediante arbitraje favorablemente 16 de diciembre de 2020.

In the municipality, nine attractiveness factors were analyzed: Human resources, infrastructure, companies, research and development, market, fiscal policy, institutions, government, and legal and social framework. It was found that of these nine factors, only the human resources factor was considered acceptable, obtaining a score of 3.77; the rest of the factors did not exceed the minimum level of 3.5, which is why they are considered unacceptable. The factors with the lowest ratings were: Government and Institutions with a rating of 2.49 and 2.50 respectively. In conclusion, the city of Huatabampo presents several areas for improvement that must be addressed if it is desired to have an acceptable level of territorial attractiveness that generates conditions of constant attraction of productive investment flows.

Key words: Competitiveness, atractiveness

\section{Introducción|}

La apertura comercial ha provocado que los gobiernos intensifiquen y diversifiquen acciones tendientes a atraer a sus territorios inversión que generen desarrollo en la comunidad. Los casos van desde resaltar la abundancia de los recursos naturales, o desarrollar cualidades que cautiven a los inversionistas hasta ofrecer incentivos fiscales ligados a la inversión en determinado territorio. Lo anterior, ha originado una constante dinámica por el sector empresarial por su decisión de invertir en determinado lugar geográfico; es decir en función de su atractividad territorial (Karray \& Toumi, 2007).

De acuerdo con la Real Academia Española (2020), este vocablo es proveniente en su etimología del latín tardío "attractīvus", la cual significa adj. "Que atrae o tiene fuerza para atraer", m. "Capacidad de atraer". 
"Fl silwer ile mis hijics

Año 13.

Núm. 33

https://revistainvestigacionacademicasinfrontera.unison.mx/index.php/RDIASF
Revista de Investigación

Académica sin Frontera

ISSN: 2007-8870

Recibido el 4 de junio de 2020. Dictaminado mediante arbitraje favorablemente 16 de diciembre de 2020.

Acorde con Servillo, Atkinson y Russo (2011), desarrollan el concepto sobre la base de una visión teórica que buscan identificar a la atractividad territorial como aquella capacidad de los lugares para "atraer" y cómo esto impacta (positiva y negativamente) en los lugares en varias dimensiones.

Fue en 1997 que se implementó la palabra atractividad en México por el académico Serrano, forjando una base para implementar las referencia teóricas que solicitaban los inversionistas al seleccionar el área geográfica idónea para instalar sus negocios, donde pudieran generar un beneficio social, ser productivos y genere utilidades. A grandes rasgos, la palabra atractividad representa crear un mercado seductor en el sentido económico donde sea posible colocar negocios ya sea regional o nacional (Sánchez, 2013).

Por otro lado, Raffestin (1986), definió al término "territorio" como un reordenamiento del espacio, cuyo orden se busca en los sistemas informáticos de los cuales dispone el hombre por formar parte de una cultura. Se puede definir como el espacio que ocupa una civilización que forma parte de una sociedad exclusivamente en un territorio marcado en dimensiones específicas sin abarcar otras zonas ya ocupadas.

Así mismo, Franquet (2013) define "territorio" como un área específica de la superficie terrestre, cuyas características abarcan todos los atributos, razonablemente estables o previsiblemente cíclicos, de la biósfera de esta área, considerada verticalmente de arriba a abajo, incluyendo los de la atmósfera, el suelo con sus diferentes horizontes y el material geológico subyacente; también se incluyen la topografía, la hidrología, las poblaciones vegetales y animales, y los resultados de la actividad humana en el pasado y en el presente, en la medida que estos atributos ejercen una influencia significativa sobre los usos presentes y futuros del territorio por el hombre. 
Año 13.

Núm. 33

ISSN: 2007-8870

https://revistainvestigacionacademicasinfrontera.unison.mx/index.php/RDIASF

Recibido el 4 de junio de 2020. Dictaminado mediante arbitraje favorablemente 16 de diciembre de 2020.

Acorde con Guzmán (2019), se puede definir "atractividad territorial” como la capacidad de un espacio geográfico para atraer y retener empresas que estén dispuestas a invertir en su región, ofreciendo un lugar apropiado para la empresa y contando con las cualidades solicitadas por el inversionista; como son carreteras, infraestructura, luz eléctrica, servicio de agua potable, terreno amplio, bancos y recursos humanos capaces de laborar en dicha empresa.

Luego entonces, para determinar la atractividad territorial o las variables que atraigan a los hombres de negocios, destaca como uno de los factores llamativos la existencia de los procesos de aglomeración tanto industriales como comerciales y de servicios ya que "la aglomeración geográfica resulta de la mayor importancia relativa de las fuerzas de atracción sobre aquellas de repulsión” (Sánchez, 2013, p.78).

Como se mencionó, se puede inferir que "atractividad" es la capacidad de atraer mediante el desarrollo de cualidades que cautivan a una persona, y claro, en un sentido empresarial, es la capacidad de atraer inversiones a un lugar mostrando las cualidades de una zona y convenciendo al inversionista para posicionar su empresa en una región o zona geográfica determinada.

Luego entonces, se puede considerar que la identificación de áreas de oportunidad relacionadas con factores de atractividad territorial en el municipio de Huatabampo, contribuyen a la toma de decisiones estratégicas que coadyuvan al aumento de las inversiones productivas en el municipio y traer con esto, la mejora en el bienestar de sus habitantes. Por ende, cada nación, estado o región, buscan el bienestar económico y social para todos sus habitantes, una de las formas de lograrlo es la creación de oportunidades mediante la atracción de inversiones, generando un incremento en los índices de empleo y claro, una derrama económica importante para una región específica, mejorando así, la calidad de vida de sus habitantes en temas de desarrollo económico y prosperidad. 
"Fl silwer ile mis hijics

Año 13.

Núm. 33

https://revis

Recibido el 4 de junio de 2020. Dictaminado mediante arbitraje favorablemente 16 de diciembre de 2020.

Es así como los estados y ciudades tienen la oportunidad de explotar sus capacidades y las ventajas competitivas que poseen sus territorios, demostrando que la región puede ser atractiva para la atracción de la ID o IED, teniendo la certeza de que tomaron una buena decisión. De esta forma se contribuye a alcanzar el objetivo de crear estabilidad económica y prosperidad en los habitantes.

En esta tesitura, Cusin y Damon (2011), afirman que la atractividad se percibe como un elemento determinante de la competitividad, no obstante, no se reduce a las dimensiones puramente económicas de los territorios, sino que explora la oportunidad de enfocarse ésta a temas de su nivel de influencia sobre los actores, su capacidad de generar movimiento, llegando hasta las dimensiones propiamente urbanas, sociales, culturales y políticas de los territorios (pp. 86-87).

Por su parte Furio (2006), comenta que para muchos investigadores ambos conceptos están vinculados estrechamente, dado que la competitividad se visualiza como la capacidad ya sea de una empresa o de una región, inclusive de un país "para conservar o mejorar su posición frente a la competencia de otras unidades económicas comparables". Lo anterior indica que no basta con disponer de vastos recursos naturales para inducir la inversión en él; agrega señalando que la apertura a la inversión de las economías de Europa oriental por ejemplo, ha incrementado la competencia regional por atraer los recursos necesarios para los nuevos mercados y negocios en esos y en otros países.

Así, también este autor considera que la globalización y el auge producido por el comercio exterior han propiciado la movilidad de factores de la producción como el capital y el trabajo (en particular el altamente calificado) y ello induce a pensar como experto en planeación sobre cuáles deben ser "las variables que influyen en la recepción de un territorio de los factores productivos". En otras palabras su interés se centra en la identificación de las variables que hacen "atractivo" 
Año 13.

Núm. 33

ISSN: 2007-8870

https://revistainvestigacionacademicasinfrontera.unison.mx/index.php/RDIASF

Recibido el 4 de junio de 2020. Dictaminado mediante arbitraje favorablemente 16 de diciembre de 2020.

un espacio y su economía para atraerlos, es decir, en determinar su capacidad para seducir el asentamiento del capital, el trabajo y las innovaciones tecnológicas en ellos (Furio, 2006, p. 3).

Uno de los papeles más importantes en dicho proceso es la inversión, cada región debe tener la capacidad de atraer inversiones. Para lograrlo, es necesario percibir y analizar los indicadores que los inversionistas consideran para la toma de decisiones. La comunidad científica (Bozzano, 2000; Lara, 2017; Guzmán, 2019), expone que son diversos factores que inciden en la atractividad territorial entre los que destacan y son concurrentes se enlistan: a) Recursos humanos, b) infraestructura, c) empresa, d) investigación y desarrollo, e) mercado, f) política fiscal, g) instituciones, h) gobierno y i) marco jurídico-social.

En el ámbito internacional, los problemas de la atractividad territorial no son exclusivos de México, es decir, acorde a Elisei, Leopa y Miruna (2018), las políticas socioeconómicas situadas en el sudeste de Europa, presentan grandes retos para consolidar la atractividad en las ciudades y regiones ya que ante la crisis generalizada, estas enfrentan dificultades de implementación. Por ello, se necesita un enfoque concertado para abordar la causa y no el efecto de las tendencias a la baja, sino también para aprovechar las muchas oportunidades del día: ¿por qué es "mejor" en otros lugares, o no es lo suficientemente atractivo aquí?, ¿Cómo se define, se califica y se fortalece el atractivo territorial a nivel nacional? (p. 13).

Mediante el diagnóstico de los factores de atractividad territorial, en el municipio de Huatabampo se determinaron aquellos indicadores que se encuentran en un nivel aceptable y, al mismo tiempo detectar aquellos factores susceptibles de ser mejorados, para de esta manera realizar un plan de acción enfocado a hacer más atractivo el municipio para los inversionistas. 
"Fl silwer ile mis hijics

Año 13.

Núm. 33

https://revistainvestigacionacademicasinfrontera.unison.mx/index.php/RDIASF
Revista de Investigación

Académica sin Frontera

ISSN: 2007-8870

Recibido el 4 de junio de 2020. Dictaminado mediante arbitraje favorablemente 16 de diciembre de 2020.

La presente investigación se llevó a cabo debido a que, pese a los esfuerzos por atraer más inversión a los municipios en el sur de Sonora, pareciera ser que estos esfuerzos no han sido acorde a los avances que otros municipios colindantes han tenido. Por otro lado, se sabe que, no todos los municipios poseen las mismas capacidades para la atracción de inversiones, por ello, es menester identificar las áreas de oportunidad relevantes donde se pueda mejorar y ser atractivos a cualquier inversionista en el municipio de Huatabampo, Sonora. Se considera que mediante la identificación y análisis de la percepción que tienen los inversionistas sobre los factores de atractividad territorial, se contribuya en el diseño de estrategias encaminadas a mejorar el nivel de atractividad de este municipio.

\section{Materiales y métodos}

De acuerdo con Hernández, Fernández y Baptista (2010), esta investigación fue cuantitativa, ya que se procedió a la recolección de datos para la aplicación de un análisis estadístico básico; primero, se identificó la percepción que los empresarios locales tienen sobre aquellos factores de atractividad que son necesarios para que el municipio sea atractivo a los inversionistas, procesándose la misma con el IRF. La investigación fue no experimental, es decir, no se manipularon deliberadamente las variables. Se observaron los fenómenos tal y como se dan en su contexto natural, para su análisis. Fue transeccional porque se recolectaron los datos del sector empresarial en un solo momento, en un tiempo único.

Los sujetos de estudio fueron 46 empresarios del municipio de Huatabampo, Sonora, para los efectos del estudio se utilizó la fórmula para la obtención de muestras con poblaciones finitas (Aguilar, 2005), 
"Fl silwer ile mis hijics

Año 13.

Núm. 33

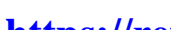

Revista de Investigación

Académica sin Frontera

ISSN: 2007-8870

Recibido el 4 de junio de 2020. Dictaminado mediante arbitraje favorablemente 16 de diciembre de 2020.

$$
\eta=\frac{\left[Z^{2} *(\rho q \eta)\right]}{\left[N \varepsilon^{2}+Z^{2} * \rho q\right]}
$$

y la fórmula para muestras pequeñas de Mateu y Casal (2003),

$$
\eta^{\prime}=\frac{1}{\left[\frac{1}{\mathrm{~N}}+\frac{1}{\eta}\right]}
$$

determinándose finalmente una muestra de 22 empresas, mismas que fueron seleccionadas de manera aleatoria, dato obtenido del Sistema de Información Empresarial Mexicano, con una probabilidad de ocurrencia del 0.5 y nivel de confianza del $95 \%$.

El procedimiento para esta investigación contempló 5 pasos:

1. Se realizó una investigación para la identificación de los factores de atractividad considerados más importantes para los inversionistas. Se determinó evaluar nueve factores: Recursos humanos, infraestructura, empresas, investigación y desarrollo, mercado, política fiscal, instituciones, gobierno, marco jurídico y social.

2. Se elaboró instrumento tipo escala Likert (Malave, 2007) con 79 reactivos para la medición de los diferentes factores a evaluar. Las respuestas más positivas obtienen la puntuación igual a 5 y las más negativas son codificadas con un valor de 1. Para el factor Recursos humanos se midieron 11 elementos, para infraestructura 10, para empresas 21, para investigación y desarrollo 4, para mercado 8, para política fiscal 5, para instituciones 6, para gobierno 7, y para marco jurídico y social 7 elementos. Adicionalmente, se les presentó a los empresarios ocho opciones, denominadas nuevas tendencias de atractividad, para que opinaran cuales de estas pudieran, en su opinión, desarrollarse en el municipio para aumentar el atractivo para los inversionistas. Finalmente, se les 
"Fl silwer ile mis hijics

Año 13.

Núm. 33

https://revistainvestigacionacademicasinfrontera.unison.mx/index.php/RDIASF
Revista de Investigación

Académica sin Frontera

ISSN: 2007-8870

Recibido el 4 de junio de 2020. Dictaminado mediante arbitraje favorablemente 16 de diciembre de 2020.

preguntó a los empresarios, el grado de importancia en una escala del 1 al 10, otorgado por ellos a cada uno de los nueve factores de atractividad estudiados en esta investigación

3. Se realizó una prueba piloto para medir la confiabilidad y validez del cuestionario. El Alpha de Cronbach fue de 0.88 determinándose así un instrumento confiable.

4. Se realizó el trabajo de campo, que consistió en entrevistar a 22 empresas de la ciudad de Huatabampo, Sonora; aplicándose el instrumento entre el 15 de enero de 2020 y el 30 de marzo de 2020.

5. Se procesaron los datos obtenidos dándole un tratamiento estadístico descriptivo utilizando programa Excel 2019 (v19.0) para determinar los resultados de la investigación. El criterio que se utilizó para interpretar los resultados del instrumento con una escala de Likert de 5 puntos fue considerando el siguiente rango: que las respuestas mayores o iguales a 3.5 son consideradas aceptables y respuestas menores a 3.5 se consideran como no aceptables. Este rango tiene el propósito de que los factores que puedan ser evaluados como "Ni de acuerdo ni en desacuerdo", sean contemplados como factores que requieren ser atendidos para mejorar el nivel de atractividad.

\section{Resultados y discusiones}

Como parte de la investigación, los resultados obtenidos sobre los factores de atractividad territorial, contemplan tres apartados importantes. En el primer apartado se les preguntó a los empresarios su percepción respecto a nueve factores de atractividad que incluyen diversos elementos en cada uno de ellos; en el segundo apartado se cuestiona sobre las posibilidades que tiene el municipio bajo estudio sobre las tendencias de atractividad territorial y en el tercer apartado se refiere a identificar qué factores de atractividad son más importantes en la opinión de los empresarios. 
"Fl silwer ile mis hijics

Año 13.

Núm. 33

https://revistainvestigacionacademicasinfrontera.unison.mx/index.php/RDIASF
Revista de Investigación

Académica sin Frontera

ISSN: 2007-8870

Recibido el 4 de junio de 2020. Dictaminado mediante arbitraje favorablemente 16 de diciembre de 2020.

\section{Percepción de factores de atractividad territorial.}

Del primer apartado de la información obtenida en donde los empresarios ofrecieron su percepción sobre diversos factores de atractividad, el resultado que se obtuvo del factor Recursos Humanos en términos generales es aceptable ya que la media fue de 3.72; sin embargo, se detectaron dos elementos que la media está en el rango de no aceptable: uno de ellos fue sobre el municipio cuenta con universidades que generen formación de profesionistas para las empresas (3.36) y el costo del recurso humano en la región es competitivo (3.46). Si bien es cierto estos elementos se encuentran en un nivel apenas por debajo de la media, son dos elementos que sugieren un área de oportunidad para mejorar la percepción sobre el factor de atractividad de los Recursos Humanos.

Tabla 1. Resultados del Factor Recursos Humanos.

\begin{tabular}{lr}
\hline \multicolumn{1}{c}{ Elemento evaluado } & Media \\
\hline El municipio cuenta con mano de obra calificada & 4.09 \\
El recurso humano del municipio posee actitudes como colaboración y participación & \\
que la empresa necesita & 4.00 \\
El recurso humano del municipio es productivo y eficiente & 3.86 \\
No existen problemas laborales graves como paros y huelgas en el municipio & 3.91 \\
Existe una buena cultura laboral en el municipio que se refleja en baja rotación de & \\
personal & 3.55 \\
El municipio dispone de profesionistas suficientes para cubrir las necesidades de su & \\
empresa & 3.68 \\
El municipio cuenta con recurso humano especializado necesario para su empresa & 3.86
\end{tabular}


"Fl silwer ile mis hijics

Año 13.

Núm. 33

https://revistainvestigacionacademicasinfrontera.unison.mx/index.php/RDIASF
Revista de Investigación

Académica sin Frontera

ISSN: 2007-8870

Recibido el 4 de junio de 2020. Dictaminado mediante arbitraje favorablemente 16 de diciembre de 2020.

El municipio cuenta con universidades que generen formación de profesionistas para su empresa

El municipio cuenta con buen nivel educativo de sus habitantes

El costo de los recursos humanos en la región es competitivo

El municipio cuenta con recursos humanos con especialidad productiva

Fuente: elaboración propia, con datos obtenidos de encuestas aplicadas el 30 de marzo de 2020.

En materia de Infraestructura, el resultado de la evaluación por parte de los empresarios es que se encuentra en un rango no aceptable con una media de 3.34, es decir, entre los elementos que requieren ser atendidos destacan: Infraestructura carretera con una media de 2.86, disposición suficiente de vuelos a distintas ciudades nacionales e internacionales 2.27, adecuado parque industrial 2.27 y efectivo programa de tratamiento de aguas residuales 3.32. El resto de los elementos como se aprecia son aceptables ya que se encuentran por arriba de la media, dentro de este rango la mejor media es conectividad de celular e internet.

Tabla 2. Resultados del factor Infraestructura.

\begin{tabular}{lc}
\hline \multicolumn{1}{c}{ Elemento evaluado } & Media \\
\hline El municipio provee un servicio suficiente de agua potable y drenaje de calidad & 3.50 \\
Existe un servicio de energía eléctrica adecuado y confiable & 3.55 \\
La región posee infraestructura carretera adecuada & 2.86 \\
Existe disposición suficiente de vuelos a distintas ciudades nacionales e & 2.27 \\
internacionales & 2.23 \\
Se cuenta en el municipio con un adecuado parque industrial & 3.91 \\
El municipio cuenta con una adecuada conectividad telefónica convencional &
\end{tabular}


"Fl suber ise mis hijos

Año 13.

Núm. 33

https://revistainvestigacionacademicasinfrontera.unison.mx/index.php/RDIASF
Revista de Investigación

Académica sin Frontera

ISSN: 2007-8870

Recibido el 4 de junio de 2020. Dictaminado mediante arbitraje favorablemente 16 de diciembre de 2020.

El municipio cuenta con una adecuada conectividad en telefonía celular

El municipio cuenta con una adecuada conectividad de internet

El municipio cuenta con proveedores de servicios para sistemas de cómputo

(Software y Hardware)

Existe un efectivo programa de tratamiento de aguas residuales en el municipio

\section{EVALUACIÓN MEDIA GLOBAL}

Fuente: elaboración propia, con datos obtenidos de encuestas aplicadas el 30 de marzo de 2020.

Otro factor importante para la atractividad es la Empresa, en este factor se contemplaron 21 elementos cuya evaluación general es no aceptable con una media de 3.34. Las áreas de oportunidad que destacan son: disponibilidad de maquinaria y equipo en el municipio, las empresas no tienen una filosofía de innovación constante, el municipio no ofrece condiciones para retener a las empresas, no existe un clima de cooperación entre las empresas del municipio, falta de asociaciones empresariales, las empresas no tienden a durar largo tiempo en el municipio, falta nivel de competencia, los proveedores locales requieren mejorar la calidad y cantidad, no hay una orientación hacia las exportaciones, los sueldos no son competitivos, hace falta cuidar el medio ambiente, falta del cumplimiento de empresas socialmente responsables, falta de clusters, no hay un aprovechamiento sustentable de los recursos naturales y existen deficiencias con la contaminación del aire y aguas. De todos los elementos son únicamente cinco lo que se encuentran dentro del rango aceptable. 
Año 13.

Académica sin Frontera

Núm. 33

ISSN: 2007-8870

https://revistainvestigacionacademicasinfrontera.unison.mx/index.php/RDIASF

Recibido el 4 de junio de 2020. Dictaminado mediante arbitraje favorablemente 16 de diciembre de 2020.

Tabla 3. Resultados del factor Empresa.

\begin{tabular}{l} 
Elemento evaluado \\
\hline El sector empresarial del municipio es bueno en cantidad y calidad \\
Su empresa tiene acceso suficiente y oportuno a materia prima por empresas del
\end{tabular}

municipio

Media

$\mathrm{Su}$ empresa puede adquirir maquinaria y equipo en el municipio

Las empresas del municipio tienen una filosofía de innovación constante

El municipio ofrece las condiciones adecuadas para que las empresas permanezcan

allí

Existe un clima de cooperación entre las empresas del municipio

Existen asociaciones empresariales en el municipio

Las empresas tienden a durar largo tiempo en el municipio (periodo de vida)

Existe un buen nivel de competencia entre empresas del municipio

Su empresa cuenta con un buen nivel de (calidad y cantidad) proveedores locales

Existe en el municipio una orientación hacia las exportaciones

Las empresas del municipio cuentan con sueldos competitivos que brindan

bienestar a sus trabajadores

El empresario local se preocupa por mantener un buen ambiente obrero-patronal

Las empresas del municipio cuidan el medio ambiente

La mayoría de las empresas del municipio cumplen con los preceptos de las

Empresas Socialmente Responsables

Existen en el municipio empresas exportadoras 
"Fl silwer ile mis hijics

Año 13.

Núm. 33

\section{https://revist}

Revista de Investigación

Académica sin Frontera

ISSN: 2007-8870

Recibido el 4 de junio de 2020. Dictaminado mediante arbitraje favorablemente 16 de diciembre de 2020.

Existen en el municipio empresas relacionadas especializadas en alguna actividad

o giro en común (Clusters)

Su empresa forma parte de un grupo de firmas relacionadas entre sí en una

actividad común

Se promueve en el municipio el aprovechamiento sustentable de los recursos

naturales

No existen problemas de contaminación de aire en el municipio

No existen problemas de contaminación de aguas en ríos, canales y mares en el municipio

EVALUACIÓN MEDIA GLOBAL

Fuente: elaboración propia, con datos obtenidos de encuestas aplicadas el 30 de marzo de 2020.

Acorde con la tabla 3, es importante evaluar el apoyo a investigación y desarrollo en territorios que desean ser competitivos y atractivos para nuevas empresas. Los resultados para este factor son poco favorables ya que obtuvo una media de 3.22 que se encuentra por debajo de la media aceptable, donde los cuatro elementos están en una media NO ACEPTABLE siendo detectado un importante factor para atenderse de inmediato. 
"Fl sibler ite mis hijise

Año 13.

Núm. 33

https://revistainvestigacionacademicasinfrontera.unison.mx/index.php/RDIASF
Revista de Investigación

Académica sin Frontera

ISSN: 2007-8870

Recibido el 4 de junio de 2020. Dictaminado mediante arbitraje favorablemente 16 de diciembre de 2020.

Tabla 4. Resultados del factor Investigación y Desarrollo.

\begin{tabular}{lc}
\hline \multicolumn{1}{c}{ Elemento evaluado } & Media \\
\hline Las empresas locales invierten en la innovación de sus productos y procesos & 3.23 \\
Las universidades locales apoyan a la innovación y desarrollo de las empresas & 3.18 \\
locales & 3.27 \\
Existe calidad y disponibilidad de profesionistas (ingenieros y licenciados) & 3.18 \\
egresados de las universidades locales & $\mathbf{3 . 2 2}$ \\
En la actualidad la tecnología utilizada por las empresas locales es actualizada & \\
EVALUACIÓN MEDIA GLOBAL &
\end{tabular}

Fuente: elaboración propia, con datos obtenidos de encuestas aplicadas el 30 de marzo de 2020.

Otro factor que se evalúa es el Mercado. Si bien es cierto que un producto de buena calidad puede tener mucha demanda, es imposible pensar que se puede vender en cualquier lugar sin antes haber realizado una previa investigación del mercado al cual se dirige. Es por eso la importancia de este factor que muestra una media ACEPTABLE (3.80), donde solo destaca un elemento apenas y por debajo de la media aceptable con 3.45 que señala que el municipio no ha demostrado ser rentable para el comercio e industria de la región.

Tabla 5. Resultados del factor Mercado.

\begin{tabular}{lc}
\hline \multicolumn{1}{c}{ Elemento evaluado } & Media \\
\hline El mercado del municipio es de un tamaño adecuado para la venta de sus & 4.05 \\
productos y/o servicios & 3.95 \\
El mercado del municipio tiene una tasa de crecimiento favorable para su negocio & 3.68 \\
El mercado del municipio tiene buena capacidad de compra &
\end{tabular}


"Fl suler ile mis hiips

Año 13.

Núm. 33

hutps:/1revist
Revista de Investigación

Académica sin Frontera

ISSN: 2007-8870

Recibido el 4 de junio de 2020. Dictaminado mediante arbitraje favorablemente 16 de diciembre de 2020.

Su empresa enfrenta una alta competencia en el municipio

El consumidor local tiende a adquirir lo que se produce en la región

El consumidor local es exigente y sofisticado en las compras que realiza

Su empresa ha tenido que adaptar su oferta de productos y/o servicios debido a exigencias de sus consumidores (Gustos, modas, competencia)

El municipio ha demostrado ser rentable para el comercio e industria de la región

EVALUACIÓN MEDIA GLOBAL

Fuente: elaboración propia, con datos obtenidos de encuestas aplicadas el 30 de marzo de 2020.

Un factor importante a evaluar es la Política fiscal, ya que las empresas también buscan los apoyos económicos del gobierno mediante facilidades para establecerse en un lugar. Después de encuestar a los empresarios, se determinó que el factor se encuentra en un rango NO ACEPTABLE con una media de 3.29 y con ninguno de los elementos en el rango aceptable, donde destaca como más bajo el considerar cerrar las operaciones en el municipio dada la carga fiscal de la empresa, lo que enciende los focos rojos ya que de no atenderse, las empresas establecidas ya en dicho territorio podrían cerrar para emigrar a otro lugar. 
"Fl silwer ile mis hijics

Año 13.

Núm. 33

https://revistainvestigacionacademicasinfrontera.unison.mx/index.php/RDIASF
Revista de Investigación

Académica sin Frontera

ISSN: 2007-8870

Recibido el 4 de junio de 2020. Dictaminado mediante arbitraje favorablemente 16 de diciembre de 2020.

Tabla 6. Resultados del factor Política fiscal.

\begin{tabular}{lc}
\hline \multicolumn{1}{c}{ Elemento evaluado } & Media \\
\hline La política fiscal de la región facilita la apertura de nuevas empresas & 3.32 \\
La política fiscal facilita el crecimiento de las empresas del municipio & 3.41 \\
Existen estímulos fiscales adecuados que fomenten la apertura y permanencia de & 3.23 \\
empresas en el municipio & \\
Los gastos físcales que asumen las empresas del municipio es equilibrada y & 3.27 \\
permite la viabilidad de la empresa & \\
Al inicio de sus operaciones empresariales la política fiscal era más favorable para & 3.41 \\
la apertura de nuevos negocios & \\
Ha considerado alguna vez, cerrar operaciones en el municipio dada la carga fiscal & 3.09 \\
de su empresa & $\mathbf{3 . 2 9}$ \\
EVALUACIÓN MEDIA GLOBAL &
\end{tabular}

Fuente: elaboración propia, con datos obtenidos de encuestas aplicadas el 30 de marzo de 2020.

Para muchas empresas es importante las instituciones con la que cuenta el municipio, ya que algunas dependen mucho de estas. Se determinó que el municipio está en el rango aceptable en cuanto a sus instituciones con una media de 3.86, al igual que cada elemento evaluado todos por encima de la media aceptable; si bien es cierto que no se tiene problema en este factor, es importante no dejarlo de lado y estar atento a cualquier cambio que pudiera ser aún más favorable.

Tabla 7. Resultados del factor Instituciones.

\begin{tabular}{lr}
\hline \multicolumn{1}{c}{ Elemento evaluado } & Media \\
\hline El municipio cuenta con un sistema bancario adecuado a sus necesidades & 4.14 \\
$\begin{array}{l}\text { Existe facilidad para un emprendedor local para conseguir financiamiento para } \\
\text { nuevos proyectos }\end{array}$ & 3.77
\end{tabular}


Año 13.

Núm. 33

ISSN: 2007-8870

https://revistainvestigacionacademicasinfrontera.unison.mx/index.php/RDIASF

Recibido el 4 de junio de 2020. Dictaminado mediante arbitraje favorablemente 16 de diciembre de 2020.

Existen adecuados servicios de salud en el municipio

Existe una adecuada seguridad pública en el municipio

Existe una adecuada oferta educativa en el municipio

Existen organismos de protección civil como bomberos, cruz roja y otros en el municipio

Fuente: elaboración propia, con datos obtenidos de encuestas aplicadas el 30 de marzo de 2020.

Gran influencia tiene en la atractividad de un municipio la intervención del gobierno local, ya que es a quien se dirige primeramente el inversionista para establecer su empresa en un lugar. Al realizarse la evaluación de este factor se obtuvo una media que se considera como no aceptable ya que la calificación de este elemento fue de 3.25, destacando que el gobierno local es quien debe de apoyar, promover y facilitar la apertura de nuevas empresas (3.27), los funcionarios del gobierno municipal deben de conducirse con ética y honestidad con las empresas (3.23), el gobierno debe de promover un ambiente de fomento económico (3.09). Siendo estas las que se encuentran por debajo de la media aceptable; empero, los elementos en el rango aceptable están apenas por encima de este, lo que obliga a también prestar atención en estos para evitar que caigan al rango por debajo de la media.

Tabla 8. Resultados del factor Gobierno.

\begin{tabular}{lr}
\hline \multicolumn{1}{c}{ Elemento evaluado } & Media \\
\hline El gobierno local apoya, promueve y facilita la apertura de nuevas empresas & 3.27 \\
Los funcionarios del gobierno municipal se conducen con ética y honestidad con & \\
las empresas & 3.23 \\
Al elaborar los planes y programas de gobierno se toman en cuenta a todos los \\
sectores de la economía regional
\end{tabular}


"Fl suber ise mis hijisa

Año 13.

Núm. 33
Revista de Investigación

Académica sin Frontera

ISSN: 2007-8870

https://revistainvestigacionacademicasinfrontera.unison.mx/index.php/RDIASF

Recibido el 4 de junio de 2020. Dictaminado mediante arbitraje favorablemente 16 de diciembre de 2020.

Cumplir con la reglamentación municipal no supone una carga adicional a la empresa

El gobierno promueve un ambiente de fomento económico

La incidencia de delincuencia en el municipio no impone costos adicionales a la empresa

Existe una policía confiable en el municipio

EVALUACIÓN MEDIA GLOBAL

Fuente: elaboración propia, con datos obtenidos de encuestas aplicadas el 30 de marzo de 2020.

Además de lo anterior, otro factor que resulta interesante mencionar es con respecto a el marco jurídico y social, factor importante que hay que tomar en cuenta al momento de querer invertir y establecer una empresa en algún territorio, es de suma importancia para el inversionista estudiar y empaparse de las leyes que rigen el lugar donde se piensa invertir y al final tomar la decisión más viable. Esta evaluación obtuvo una media global del 3.43 lo que significa que está en el rango no aceptable, mismo donde destacan los elementos como: a) Disponibilidad adecuada para adquisición de bienes inmuebles con certeza jurídica (3.18), b) las leyes, reglamentos y directivas a las que debe ceñirse la empresa permiten el desarrollo de las empresas del municipio (3.45), c) la aplicación de las leyes y reglamentos en el municipio es sin trato preferencial (3.32), d) existe una adecuada impartición de justicia en el municipio (3.14), e) los organismos de impartición de justicia en el municipio son confiables (3.18). Los tres elementos restantes se encuentran dentro del rango aceptable, por lo que se deben atender los antes mencionados. 
"Fl sibler ite mis hijise

Año 13.

Núm. 33

\section{hutps:/1revist}

Revista de Investigación

Académica sin Frontera

ISSN: 2007-8870

Recibido el 4 de junio de 2020. Dictaminado mediante arbitraje favorablemente 16 de diciembre de 2020.

Tabla 9. Resultados del factor Marco jurídico y social.

\section{Elemento evaluado}

Disponibilidad adecuada para adquisición de bienes inmuebles con certeza jurídica

Las leyes, reglamentos y directivas a las que debe ceñirse la empresa permiten el

desarrollo de las empresas del municipio

La aplicación de las leyes y reglamentos en el municipio es sin trato preferencial

Existe en general una adecuada y cordial convivencia social entre los habitantes

del municipio

Existe un clima social propicio para la inversión en el municipio

Existe una adecuada impartición de justicia en el municipio

Los organismos de impartición de justicia en el municipio son confiables

EVALUACIÓN MEDIA GLOBAL
Media

3.18

3.43

Fuente: elaboración propia, con datos obtenidos de encuestas aplicadas el 30 de marzo de 2020.

El concentrado de los resultados globales de los nueve factores muestra que solo dos de ellos se encuentran en el rango de aceptables: Mercado con una media 3.80 y Recursos humanos con 3.72. Se encontró que existen siete factores en donde hay áreas de oportunidad, resaltando que los factores peor evaluados son: Investigación y desarrollo con una media de 3.22, Gobierno con una media de 3.25 y política fiscal con una media de 3.29. 
"Fl solber ile mis hiigs

Año 13.

Núm. 33

https://revistainvestigacionacademicasinfrontera.unison.mx/index.php/RDIASF

Revista de Investigación

Académica sin Frontera

ISSN: 2007-8870

Recibido el 4 de junio de 2020. Dictaminado mediante arbitraje favorablemente 16 de diciembre de 2020.

Tabla 10. Concentrado de resultados globales de percepción factores de atractividad.

\begin{tabular}{|c|c|c|}
\hline Factor de atractividad & Rango & Media \\
\hline Recursos humanos: Mano de obra calificada, Profesi & Aceptable & 3.72 \\
\hline $\begin{array}{l}\text { Infraestructura: Carreteras, agua potable, Aeropuertos, energía, } \\
\text { Internet, telefonía, etc. }\end{array}$ & $\begin{array}{c}\text { No } \\
\text { aceptable }\end{array}$ & 3.34 \\
\hline Empresas: Proveedores disponibles, Cooperación entre Empresas, etc. & $\begin{array}{l}\text { No } \\
\text { aceptable }\end{array}$ & 3.33 \\
\hline $\begin{array}{l}\text { Investigación y Desarrollo: Acceso a investigadores, Desarrollo de } \\
\text { innovaciones e investigación. }\end{array}$ & $\begin{array}{l}\text { No } \\
\text { aceptable }\end{array}$ & 3.22 \\
\hline $\begin{array}{l}\text { Mercado: Tamaño, dinamismo, Potencial del crecimiento, nivel de } \\
\text { competencia, etc. }\end{array}$ & Acep & 3.80 \\
\hline $\begin{array}{l}\text { Política fiscal: Nivel de impuestos, Fomento e incentivos fiscales para } \\
\text { apertura de empresas, etc. }\end{array}$ & $\begin{array}{l}\text { No } \\
\text { aceptable }\end{array}$ & 3.29 \\
\hline Instituciones: Bancos, escuelas, acceso a La salud, seguridad pública & Aceptable & 3.86 \\
\hline Gobierno: Apoyo, fomento económico, seguridad, etc. & $\begin{array}{c}\text { No } \\
\text { aceptable }\end{array}$ & 3.25 \\
\hline Marco jurídico y social: Convivencia y aplicación de la ley & No & 3.43 \\
\hline
\end{tabular}

Fuente: elaboración propia, con datos obtenidos de encuestas aplicadas el 30 de marzo de 2020.

\section{Nivel de importancia de los factores de atractividad}


"Fl sibler ite mis hijise

Año 13.

Núm. 33

https://revistainvestigacionacademicasinfrontera.unison.mx/index.php/RDIASF
Revista de Investigación

Académica sin Frontera

ISSN: 2007-8870

Recibido el 4 de junio de 2020. Dictaminado mediante arbitraje favorablemente 16 de diciembre de 2020.

También se les preguntó a los empresarios que mencionaran que nivel de importancia le daban a cada factor de atractividad, considerando una escala del 1 al 10 donde 1 es menos importante y 10 el más importante, de los valores asignados se obtuvo los siguientes promedios:

Tabla 11. Grado de importancia que tiene el factor de atractividad en opinión de los empresarios del municipio.

\section{Factor de atractividad}

Recursos humanos: Mano de obra calificada, Profesionistas

Infraestructura: Carreteras, agua potable, Aeropuertos, energía, Internet, telefonía, etc.

Empresas: Proveedores disponibles, Cooperación entre Empresas, etc.

Investigación y Desarrollo: Acceso a investigadores, Desarrollo de innovaciones e investigación
Calificación

8.23

8.05

6.45

Mercado: Tamaño, dinamismo, Potencial del crecimiento, nivel de competencia, etc.

Política fiscal: Nivel de impuestos, Fomento e incentivos fiscales para apertura de empresas, etc.

Instituciones: Bancos, escuelas, acceso a La salud, seguridad pública

Gobierno: Apoyo, fomento económico, seguridad, etc.

7.64

Marco jurídico y social: Convivencia y aplicación de la ley

7.36

Fuente: elaboración propia, con datos obtenidos de encuestas aplicadas el 30 de marzo de 2020. 
"Fl silwer ile mis hijics

Año 13.

Núm. 33

\section{https://revist}

Revista de Investigación

Académica sin Frontera

ISSN: 2007-8870

Recibido el 4 de junio de 2020. Dictaminado mediante arbitraje favorablemente 16 de diciembre de 2020.

Para los empresarios locales los factores a los que les dan mayor ponderación son a: Infraestructura, recursos humanos y mercado con calificaciones de $8.27,8.23$ y 8.14 respectivamente. Por el contrario, los factores menos relevantes son investigación y desarrollo y política fiscal obteniendo una valoración inferior a 6.5.

\section{Alternativas potenciales de atractividad territorial}

En relación a la segunda parte del cuestionario en el que se les preguntó a los inversionistas su opinión respecto de las nuevas tendencias de atractividad territorial. Se aprecia que el 55\% de los empresarios consideran que el municipio de Huatabampo tiene perfil para desarrollar la alternativa de urbanismo, es decir, que la forma como se planea, ordena y organiza una ciudad resulta en un atractivo para las personas, seguida de la alternativa Centro de logística con un $45 \%$, con lo que los empresarios consideran que el municipio puede poseer una industria muy especializada, desarrollar el puerto marítimo, líneas de ferrocarril y aeropuerto, que permita contar con una plataforma logística. El resto de las alternativas en opinión de los empresarios no tienen potencial, los resultados arrojan niveles del $32 \%$ hacia abajo. 
"Fl solber ile mis hiips

Año 13.

Núm. 33

https://revistainvestigacionacademicasinfrontera.unison.mx/index.php/RDIASF

Revista de Investigación

Académica sin Frontera

ISSN: 2007-8870

Recibido el 4 de junio de 2020. Dictaminado mediante arbitraje favorablemente 16 de diciembre de 2020.

Tabla 12. Opinión de los inversionistas sobre potencialidades que tiene el municipio de

Huatabampo, de las nuevas tendencias de atractividad territorial.

\begin{tabular}{cc}
\hline Alternativa de Atractividad & Porcentaje \\
\hline 1. Territorio digital. Adopción de un sector tecnológico específico para el
\end{tabular}

1. Territorio digital. Adopción de un sector tecnológico específico para el

desarrollo de soluciones a través de las Tecnologías de información (TICS)

$9 \%$

2. "Territorio verde". Ser una ciudad que trate con la problemática ambiental

de alcance global que permite conectar a la ciudad con todos los niveles

administrativos.

$18 \%$

3. Turismo cinematográfico. Para atraer rodajes y luego promocionar los

escenarios, rutas, etc.

4. Centro de logística. poseer una industria muy especializada, situadas cerca

de puertos marítimos, líneas de ferrocarril y aeropuertos, y se han

transformado en plataformas logísticas (multimodal)

5. Destinos para congresos, convenciones y eventos. Crear una nueva

imagen de la ciudad, primordialmente basada en la proyección exterior por

las audiencias externas que logra el evento.

6. Ciudades y territorios de origen. Cultura gastronómica y alimentaria se

utiliza para promocionar regiones específicas con el fin de atraer a inversores

a la zona, fomentar el turismo y otros negocios relacionados. Las

denominaciones de origen son los primeros soportes de imagen de marca

7. Destino de salud y bienestar. Hospitales, spas, resorts, etc.

8. Urbanismo. La forma como se planea, ordena y organiza una ciudad

resulta en un atractivo para las personas

Fuente: elaboración propia, con datos obtenidos de encuestas aplicadas el 30 de marzo de 2020. 
"Fl sibler ite mis hijise

Año 13.

Núm. 33

https://revistainvestigacionacademicasinfrontera.unison.mx/index.php/RDIASF
Revista de Investigación

Académica sin Frontera

ISSN: 2007-8870

Recibido el 4 de junio de 2020. Dictaminado mediante arbitraje favorablemente 16 de diciembre de 2020.

Finalmente en la última parte del cuestionario se realizaron preguntas abiertas a los empresarios respecto que expresaran las características que tiene el municipio y que son atractivas para que los inviertan en el municipio; las menciones que resaltan son que el municipio tiene condiciones propicias para turismo y agroindustria.

En relación a la pregunta de qué aspectos deben ser atendidos para lograr que el municipio sea más atractivo para los inversionistas; los empresarios fueron contundentes en mencionar que el tema de infraestructura es un rubro que requiere ser atendido, en menor grado se menciona la generación de empleo, apoyos para la creación de empresas y la atención de los servicios públicos.

\section{Conclusiones y recomendaciones}

Se determinó que los inversionistas son muy analíticos a la hora de seleccionar un territorio geográfico para abrir algún negocio, son principalmente nueve factores que los empresarios toman en cuenta para evaluar si un territorio tiene atractividad para la inversión: Recursos humanos, infraestructura, empresa, investigación y desarrollo, mercado, política fiscal, instituciones, gobierno y marco jurídico y social los cuales contemplan en conjunto 77 elementos diversos que sirven de apoyo para una análisis más pormenorizado de cada factor.

Se concluye que los empresarios del municipio de Huatabampo, Sonora, consideran que el municipio cuenta con servicios bancarios suficientes, se tiene buen acceso a la salud; la oferta educativa y la seguridad pública se percibe con un nivel de cumplimiento que se encuentra en el límite inferior por lo que se debe tener especial atención como área de oportunidad para mejora. En el caso del factor recursos humanos se considera que existe mano de obra y profesionistas 
"Fl suber ise mis hijos

Año 13.

Núm. 33

https://revistainvestigacionacademicasinfrontera.unison.mx/index.php/RDIASF
Revista de Investigación

Académica sin Frontera

ISSN: 2007-8870

Recibido el 4 de junio de 2020. Dictaminado mediante arbitraje favorablemente 16 de diciembre de 2020.

suficientes en cantidad y calidad, cuyo costo es muy competitivo al compararlo con otras regiones, rescatando en este rubro la oportunidad de más instituciones de educación superior que amplíen la oferta educativa. Además consideran que el tamaño del mercado es aceptable, con buen dinamismo y potencial de crecimiento, sin embargo, no ha mostrado ser rentable para el comercio e industria de la región.

Por otro lado, se concluye que son seis factores en los cuales los empresarios del municipio de Huatabampo consideran se encuentran en un nivel de no aceptable; de ahí se desprenden áreas de oportunidad susceptibles de mejora, tales como:

- Infraestructura carretera adecuada

- Conectividad aérea

- Adecuado parque industrial

- Programa efectivo de tratamiento de aguas residuales en el municipio

- Proveedores de maquinaria y equipo en el municipio

- Falta de innovación constante por parte de las empresas

- Generación de condiciones para que las empresas permanezcan

- No hay un clima de cooperación entre las empresas

- Falta orientación hacia las exportaciones

- Aprovechamiento sustentable de los recursos naturales

- Existen problemas de contaminación de aire, agua en ríos y mares en el municipio

- Apoyo en la innovación y desarrollo en las empresas por parte de las universidades

- La tecnología utilizada en las empresas no es actualizada

- La política fiscal no facilita la apertura de empresas, además limita el crecimiento de las ya existentes 
Año 13.

Núm. 33

ISSN: 2007-8870

https://revistainvestigacionacademicasinfrontera.unison.mx/index.php/RDIASF

Recibido el 4 de junio de 2020. Dictaminado mediante arbitraje favorablemente 16 de diciembre de 2020.

- El gobierno no promueve el fomento económico

- No hay confianza en los funcionarios ni en la policía municipal y el indicador de delincuencia no es aceptable.

- Insuficiente certeza jurídica para adquisición de bienes inmuebles

- La aplicación de la ley no es objetiva, por lo que la impartición de la justicia no es confiable.

Por otra parte, se concluye que los tres factores más importantes para los empresarios son infraestructura (8.27), recursos humanos (8.23), mercado (8.14) y empresas (8.05), los cuales fueron evaluados como aceptable; estratégicamente conveniente que los factores infraestructura y empresas sean los factores prioritarios de atención. Es importante destacar de los factores Instituciones (7.59), Gobierno (7.64) y Marco Jurídico y social (7.36) son medianamente importantes para los empresarios de Huatabampo; de estos, el factor instituciones es el único que es considerado como aceptable por lo que el factor gobierno y marco jurídico y social deben tomarse en cuenta en segundo término para ser atendidos como áreas de oportunidad. Finalmente, los factores que los empresarios consideran menos importantes son investigación y desarrollo y política fiscal mismos que en atención a la percepción de los empresarios no se consideran que se encuentran en un nivel de aceptable por lo que también deben ser atendidos, que si bien es cierto no son los más importantes para los empresarios, si tienen un impacto en el nivel de atractividad territorial.

Además, en opinión de los inversionistas sobre las potencialidades que tiene el municipio sobre las tendencias de atractividad territorial resulta interesante que con un $55 \%$ de menciones vean a Huatabampo con potencial para que se distinga por su urbanismo, es decir una ciudad ordenada y organizada; en segundo lugar con un $45 \%$ de menciones ven que el municipio en mención tiene potencial para centro de logística considerando una industria especializada, con 
"Fl sulber ide mis hijise

Año 13.

Núm. 33

https://revistainvestigacionacademicasinfrontera.unison.mx/index.php/RDIASF
Revista de Investigación

Académica sin Frontera

ISSN: 2007-8870

Recibido el 4 de junio de 2020. Dictaminado mediante arbitraje favorablemente 16 de diciembre de 2020.

acceso a puertos marítimos, líneas de ferrocarril y aeropuertos y en tercer lugar con un $32 \%$ de menciones consideran que el municipio puede ser atractivo para destinos para congresos, convenciones y eventos.

\section{Referencias.}

Aguilar, S. (2005). Fórmulas para el cálculo de la muestra en investigaciones de salud. Revista Salud en Tabasco, 11(1-2), pp. 333-338, ISSN: 1405-2091. Recuperado de https://www.redalyc.org/pdf/487/48711206.pdf

Bozzano, H. (2000). Atractividad territorial y cementerios industriales. Fortalezas y debilidades de la reestructuración industrial en la región metropolitana de Buenos Aires. Polígonos: Revista de Geografía (10), 137-153. En Memoria Académica. Disponible en: http://www.memoria.fahce.unlp.edu.ar/art_revistas/pr.10644/pr.10644.pdf

Cusin, F. \& Damon, J. (2011). La atractividad, condición de las ciudades del futuro: clasificaciones, retos y estrategias urbanas. Revista Sotavento, (18)1, ISSN: 01233734. Recuperado de https://revistas.uexternado.edu.co/index.php/sotavento/article/view/2972

Elisei, P., Leopa, S. \& Miruna, D. (2018). Territorial attractiveness monitoring plataform: a handbook for policy planners. European Union Founds. ISBN: 978-973-0-27980-1. Recuperado de http://www.interregdanube.eu/uploads/media/approved_project_output/0001/25/064d81849140676a3f2a 51001d860b3d710abbd3.pdf 
"Fl suber ise mis hijisa

Año 13.

Núm. 33

https://revistainvestigacionacademicasinfrontera.unison.mx/index.php/RDIASF
Revista de Investigación

Académica sin Frontera

ISSN: 2007-8870

Recibido el 4 de junio de 2020. Dictaminado mediante arbitraje favorablemente 16 de diciembre de 2020.

Franquet, J. M. (2013). Un modelo racional de organización territorial: aplicación a Cataluña (Tesis doctoral). Recuperado de http://www.eumed.net/tesisdoctorales/2007/jmfb2/4.htm

Furio, E. (2006). La Atractividad Económica de los Territorios. Recuperado de https://halshs.archives-ouvertes.fr/halshs-00119640/document

Guzmán, A. (2019). La atractividad territorial: análisis de los factores que influyen en el desarrollo turístico de los destinos. Journal of tourism and heritage research, (2)3, pp. 408-429. Recuperado de http://www.jthr.es/index.php/journal/article/download/64/112/\#: :text=La\%20comunidad \%20cient\%C3\%ADfica\%20sostiene\%20que,2017\%2C\%20Fabry\%3B\%202009

Hernández, R. Fernández, C. \& Baptista, M. (2010). Metodología de la investigación.

McGraw Hill 5ta Ed. México pág. 375-380.

Karray, Z. \& Toumi, S. (2007). Investissement Direct Étranger et Attractivité Appréciation et enjeux pour la Tunisie. Revue d'Économie Régionale \& Urbaine, octubre, (3), pp. 479501. doi:10.3917/reru.073.0479.

Lara, R. (2017). Lo smart como dispositivo de atractividad territorial: revisión del caso de tequila como destino turístico inteligente. Recuperado de https://www.researchgate.net/publication/332083149_LO_SMART_COMO_DISPOS ITIVO_DE_ATRACTIVIDAD_TERRITORIAL_REVISION_DEL_CASO_DE_TE QUILA_COMO_DESTINO_TURISTICO_INTELIGENTE

Malave, N. (2007). Escala tipo Likert. Trabajo modelo para enfoques de investigación acción participativa. http://uptparia.edu.ve/documentos/F\%C3\%ADsico\%20de\%20Escala\%20Likert .pdf 
"Fl silwer ile mis hijics

Año 13.

Núm. 33

\section{https:/revis}

Revista de Investigación

Académica sin Frontera

ISSN: 2007-8870

Recibido el 4 de junio de 2020. Dictaminado mediante arbitraje favorablemente 16 de diciembre de 2020.

Mateu, E. \& Casal, J. (2003). Tamaño de muestra. CReSA. Centre de Recerca enSanitat Animal/ Dep. Sanitat i Anatomia Animals, Universitat Autonóma de Barcelona, 08193Bellaterra, Barcelona. Recuperado de https://investmkt.files.wordpress.com/2013/03/21_06_58_2tamanomuestra3.pdf

Raffestin, C. (1986). Ecogenèse territoriale et territorialité. En Auriac, F. \& Brunet, R. (Ed.). Espaces, jeux et enjeux. Paris: Fayard \& Fondation Diderot. Université de Geneve. Recuperado de https://archive- ouverte.unige.ch/unige:4419

Real Academia Española (2020). Definición del vocablo atractividad. Recuperado el https://dle.rae.es/?w=atractividad

Sánchez, G. (2013). Competitividad de las 32 entidades federativas de México para inducir la inversión privada y para dinamizar la demanda local. Red Internacional de Investigadores en Competitividad, (7)1. Recuperado de https://www.riico.net/index.php/riico/article/view/329

Sánchez, G. (2013). Competitividad regional de las empresas manufactureras de México: 1999-2009. Recuperado de http://www.eumed.net/libros- gratis/2013b/1339/index.htm Servillo, L., Aktinson, R. \& Russo, A. P. (2011). Territorial attractiveness in EU urban and spatial policy: a critical review and future research agenda. European urban and regional studies, 0(0). DOI: 0.1177/0969776411430289 
Año 13.

Académica sin Frontera

Núm. 33

ISSN: 2007-8870

https://revistainvestigacionacademicasinfrontera.unison.mx/index.php/RDIASF

Recibido el 4 de junio de 2020. Dictaminado mediante arbitraje favorablemente 16 de diciembre de 2020.

\section{Directorio Institucional}

Dr. Enrique Fernando Velázquez Contreras

Rector

Dr. Ramón Enrique Robles Zepeda

Secretario General Académico

Dra. Rosa María Montesinos Cisneros

Secretaria General Administrativa

Dr. Rodolfo Basurto Álvarez

Director de Vinculación y Difusión

Dra. Adriana Leticia Navarro Verdugo

Vicerrectora de la Unidad Regional Sur

Dr. Ernesto Clark Valenzuela

Director de la División de Ciencias Económicas y Sociales

Dr. Francisco Espinoza Morales

Secretario de la División de Ciencias Económico y Sociales

Dra. Leticia María González Velásquez

Jefe del Departamento de Ciencias Económico Administrativas

Dra. Lidia Amalia Zallas Esquer

Jefe de Departamento de Ciencias Sociales 
"Fl suler ide mis hiipses

Año 13.

Núm. 33

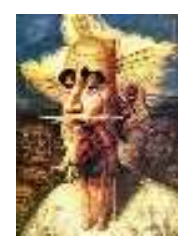

Revista de Investigación

Académica sin Frontera

ISSN: 2007-8870

https://revistainvestigacionacademicasinfrontera.unison.mx/index.php/RDIASF

Recibido el 4 de junio de 2020. Dictaminado mediante arbitraje favorablemente 16 de diciembre de 2020.

\title{
Comité Directivo
}

\author{
Editor Responsable \\ Dr. Francisco Espinoza Morales \\ Universidad de Sonora \\ Directora \\ Dra. Leticia María González Velásquez \\ Universidad de Sonora \\ Subdirector \\ Dr. Javier Carreón Guillen \\ Universidad Nacional Autónoma de México \\ Editor Científico \\ Dr. Cruz García Lirios \\ Universidad Autónoma del estado de México \\ Master Gráfico \\ M.T.I. Francisco Alan Espinoza Zallas \\ Universidad Estatal de Sonora
}

Nos complace anunciar que su diario, "Academic Research Journal Withoutborders" (ISSN/EISSN 20078870) fue evaluado positivamente en la indexación Citefactor, ahora la página de la revista está disponible en línea, en caso de cualquier problema.

Journals Master | International Innovative Journal Impact Factor (IIJIF)

Red Latinoamericana de revistas Académicas en Ciencias Sociales y Humanidades
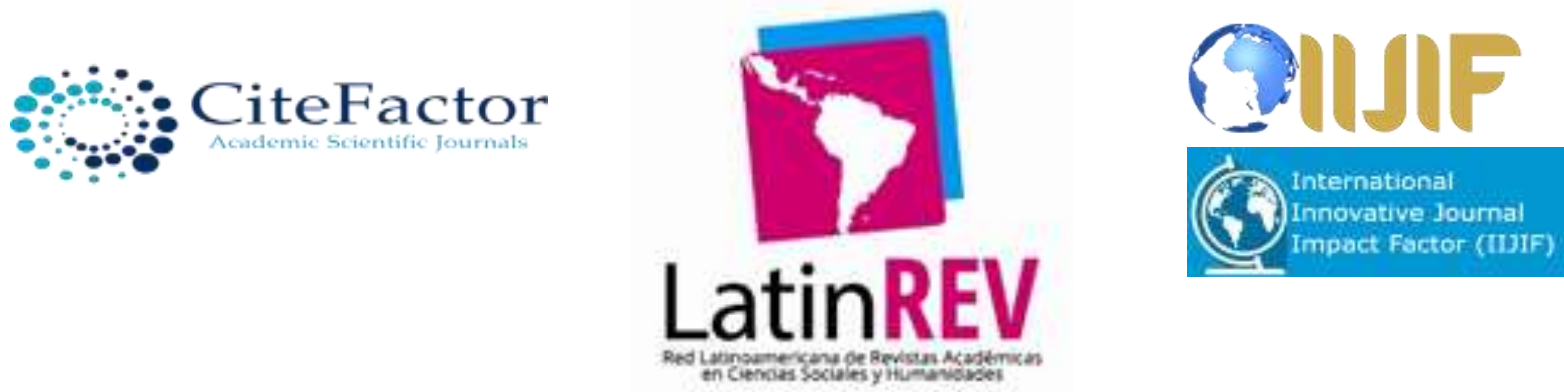
Año 13.

Académica sin Frontera

Núm. 33

ISSN: 2007-8870

https://revistainvestigacionacademicasinfrontera.unison.mx/index.php/RDIASF

Recibido el 4 de junio de 2020. Dictaminado mediante arbitraje favorablemente 16 de diciembre de 2020.

\section{Comité editorial}

Dra. Angélica María Rascón Larios

Universidad de Sonora. México

Dra. María del Rosario Molina González

Universidad de Sonora

Dra. Francisca Elena Rochin Wong

Universidad de Sonora. México

Dra. Lidia Amalia Zallas Esquer

Universidad de Sonora. México

Dra. Beatriz Llamas Arechiga

Universidad de Sonora. México

Dr. Rogelio Barba Álvarez

Universidad de Guadalajara. México

Dra. Rosa María Rincón Ornelas

Universidad de Sonora. México

Dr. Juan Flores Preciado

Universidad de Colima. México

Dr. Amado Olivares Leal. Universidad de Sonora

Universidad de Sonora. México

Dr. Guillermo Velázquez Valadez.

Instituto Politécnico Nacional (IPN) México

Dr. Hugo Nefstalí Padilla Torres.

Universidad Estatal de Sonora. México

Dr. Luis Ramón Moreno Moreno.

Universidad Autónoma de Baja California. México

Dr. Miguel Ángel Vázquez Ruiz.

Universidad de Sonora. México 
"Fl suler ide mis hiipses

Año 13.

Núm. 33
Revista de Investigación

Académica sin Frontera

ISSN: 2007-8870

https://revistainvestigacionacademicasinfrontera.unison.mx/index.php/RDIASF

Recibido el 4 de junio de 2020. Dictaminado mediante arbitraje favorablemente 16 de diciembre de 2020.

Dra. Lorena Vélez García.

Universidad Autónoma de Baja California. México

Dra. Pabla Peralta Miranda.

Universidad Simón Bolívar, Barranquilla, Colombia

Mtro. Roberto Espíritu Olmos

Universidad de Colima (FCA Tecomán) Colima

Dr. Héctor Priego Huertas.

Universidad de Colima (FCA Tecomán) Colima

Mtra. María Guadalupe Alvarado Ibarra.

Universidad de Sonora. México.

MSc. Celso Germán Sánchez Zayas

Universidad de Camagüey, Ignacio Agramonte Loynaz, Cuba

Dra. María Luisa Quintero Soto

Universidad Autónoma del Estado de México

Dr. Eyder Bolivar Mojica

Universidad Católica, Luis Amigó, Medellin, Colombia

Revisores de Textos en Inglés

Mtro. Renato Encinas

Mtra. Cecilia Guadalupe Martínez Solano

\section{Comité científico}

Dr. Rosendo Martínez Jiménez. Universidad Autónoma Benito Juárez de Oaxaca.

Dr. Hugo Neftalí Padilla. Universidad Estatal de Sonora

Dra. María Teresa Gaxiola Sánchez. Universidad de Sonora.

Dr. José Cesar Kaplan. Universidad Estatal de Sonora.

Dr. Alfredo Islas Rodríguez. Universidad de Sonora

Frecuencia de publicación: semestral / 2 números por año. 


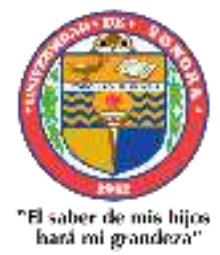

( Julio - Diciembre 2020)

Año 13.

Revista de Investigación

Núm. 33

Académica sin Frontera

ISSN: 2007-8870

https://revistainvestigacionacademicasinfrontera.unison.mx/index.php/RDIASF

Recibido el 4 de junio de 2020. Dictaminado mediante arbitraje favorablemente 16 de diciembre de 2020.

Revista de Investigación Académica sin Frontera (RIASF) con (ISSN: 2007-8870) es un interlocutor internacional de acceso abierto revisado diario en línea en el ámbito del de las Ciencias Económicas Administrativas y Sociales. Su objetivo principal es dar a los trabajos de investigación de calidad. Cubre todas las sub-campos de los campos anteriormente mencionados. Proporciona la plataforma a académicos, estudiantes y profesionales. Sólo pública trabajos de investigación y artículos de revisión inicial. Documento presentado debe cumplir con algunos criterios como, debe ser original, inédita y no estén sometidos a ninguna otra revista.

RIASF es una revista arbitrada / Revisión por pares International. Publicamos documentos sobre una variedad de temas, contextos y estrategias de análisis que examinan la relación entre la rápida evolución para la Sociedad y la tecnología del conocimiento.

REVISTA DE INVESTIGACIÓN ACADÉMICA SIN FRONTERA, Año 13, No. 33, Julio - diciembre 2020, es una publicación semestral de investigación científica, editada por la Universidad de Sonora, a través de las División de Ciencias Económicas y Sociales, de la Unidad Regional Sur, Blvd. Lázaro Cárdenas No. 100, Col. Francisco Villa, Navojoa, Sonora, Sonora, México, C.P. 85880. Tel. (642) 425- 99-54.

http://www.revistainvestigacionacademicasinfrontera.com/, revistaacademicasinfrontera@ unison.mx.

Editor responsable: Francisco Espinoza Morales. Reserva de Derechos al Uso Exclusivo: 04-2013121811323700-203 e ISSN: 2007-8870, ambos otorgados por el Instituto Nacional de Derecho de Autor. Inscrita en el Directorio de LATINDEX, con Núm. De folio 20014, folio único 14590. Responsable de la última actualización de este Número, Unidad Informática de la Universidad de Sonora, fecha de la última modificación, 30 de diciembre 2020, indexada a Cite Factor Academic Scientific Journal y Journals Master (IIJIF) y Red Latinoamericana de Revistas Académicas en Ciencias Sociales y Humanidades, (Latín Rev). Las opiniones expresadas por los autores no necesariamente reflejan la postura del editor de la publicación. Se autoriza la reproducción total o parcial de los contenidos e imágenes en la presente publicación siempre y cuando se cuente con la autorización del editor y se cite plenamente la fuente. 
"Fl suler ide mis hiipses

Año 13.

Núm. 33

https://revis
Revista de Investigación Académica sin Frontera ISSN: 2007-8870

Recibido el 4 de junio de 2020. Dictaminado mediante arbitraje favorablemente 16 de diciembre de 2020.

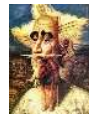

Nos complace anunciar que su diario, "Academic Research Journal Withoutborders" (ISSN/EISSN 20078870) fue evaluado positivamente en la indexación Citefactor, ahora la página de la revista está disponible en línea, en caso de cualquier problema.

Journals Master | International Innovative Journal Impact Factor (IIJIF)

\section{Red Latinoamericana de revistas Académicas en Ciencias Sociales y Humanidades}


https://www.neliti.com

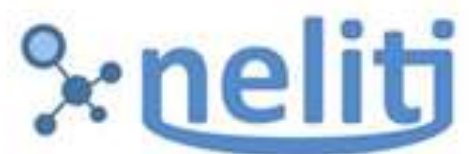

Indonesia's Research Repository
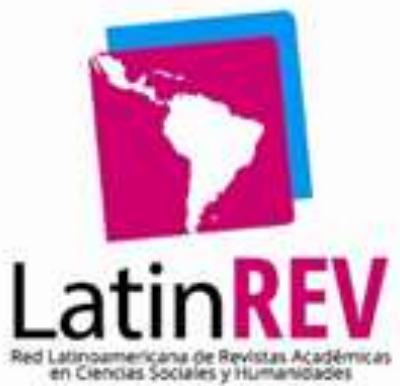

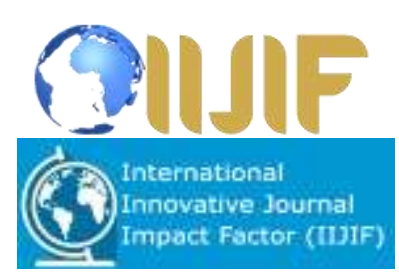

Impact Foctor (HIIF)
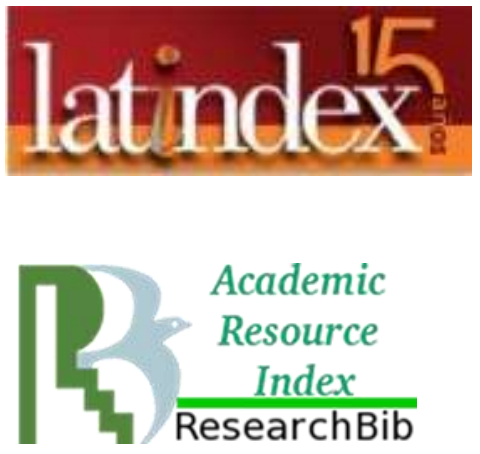
Revista de Investigación

Año 13.

Académica sin Frontera

Núm. 33

ISSN: 2007-8870

https://revistainvestigacionacademicasinfrontera.unison.mx/index.php/RDIASF

Recibido el 4 de junio de 2020. Dictaminado mediante arbitraje favorablemente 16 de diciembre de 2020. 